\title{
Erratum to: Parameter identification of electronic throttle using a hybrid optimization algorithm
}

\author{
Xiaofang Yuan • Shutao Li · Yaonan Wang • \\ Wei Sun · Lianghong Wu
}

Published online: 7 December 2010

(C) Springer Science+Business Media B.V. 2010

\section{Erratum to: Nonlinear Dyn \\ DOI 10.1007/s11071-010-9666-x}

Presented here are the correct versions of Figs. 8(a),

8(b), 9(a) and 9(b).
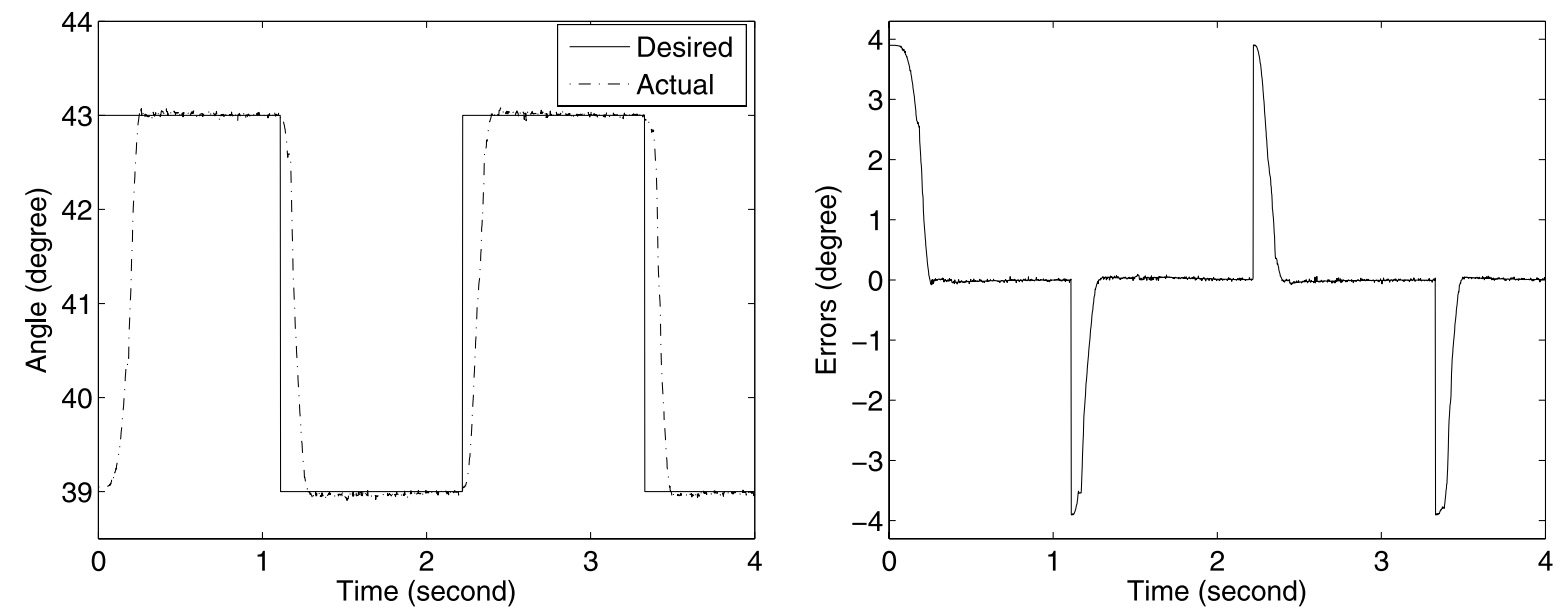

Fig. 8 Set-points tracking performance of ETC system with the identified parameter values, angle (a) and errors of angle (b)

The online version of the original article can be found under doi:10.1007/s11071-010-9666-x.

X.F. Yuan $(\bowtie) \cdot$ S.T. Li · Y.N. Wang · W. Sun · L.H. Wu College of Electrical and Information Engineering, Hunan University, Changsha 410082, People's Republic of China

e-mail: yuanxiaofang126@126.com 

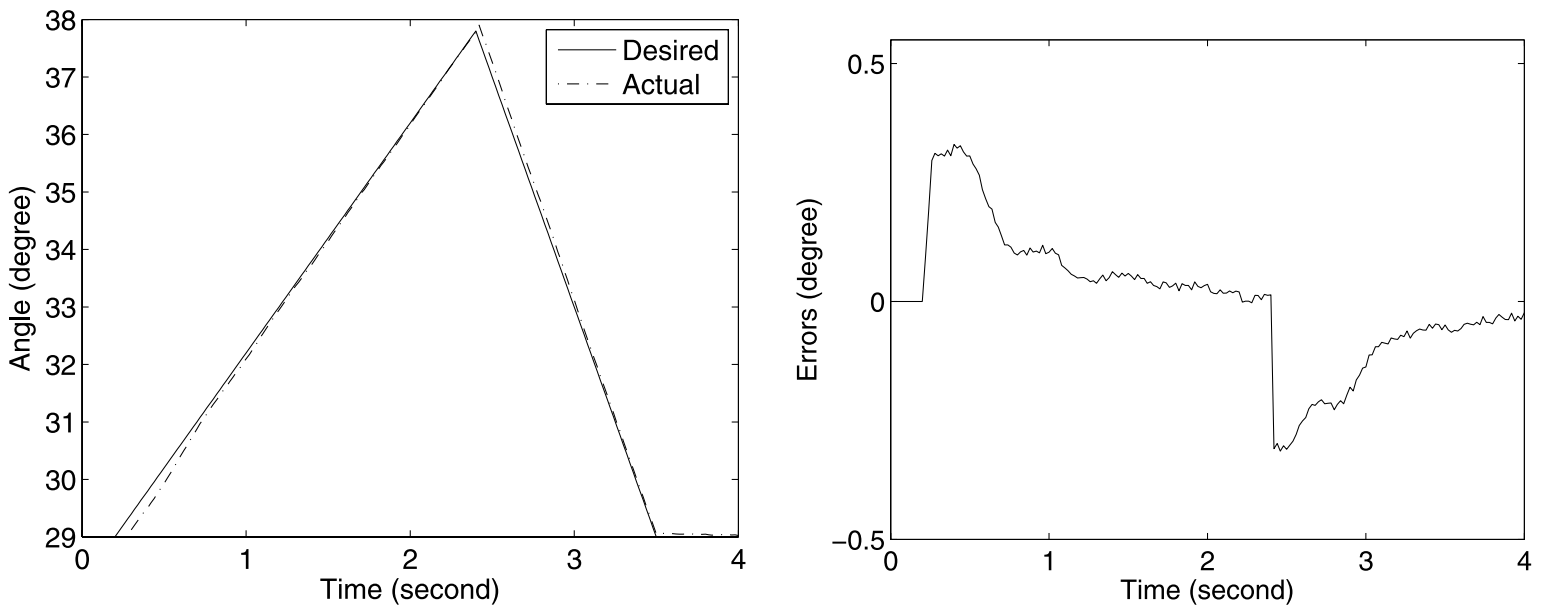

Fig. 9 Set-points tracking performance of ETC system with the identified parameter values, angle (a) and errors of angle (b) 